\title{
BIBLIOGRAPHIC NOTICES.
}

Mesmerism._Blackwood's Magazine, Feb. 1845.-p. 219.

Letters on Mesmerism.-By Harriet Martineau.

Would that every essay that has recently come before the public, on the subject of Mesmerism, had been written in the philosophical spirit with which that subject has been handled by the able and learned writer in Blackwood's Magasine, above referred to, to whom, though we cannot hail him as a professional brother, we ought to feel deeply gratified for having presented to us the result of his labours, on a subject, to which, of late, so much of public attention has been directed. His Essay, as he himself elegantly expresses of Mr. Hare Townshend's work, "stands out in prominent and ornamental relief," "from the many crude and unphilosophical speculations on the subject of mesmerism, which the present unwholesome activity of the printing press has ushered into the world." We should be glad to make copious extracts from it, but we must content ourselves with but as many as our limited space will admit of, and refer our readers for further information to the original article. We also recommend to the perusal of our readers, Doctor Forbes' account of the exhibition of mesmeric clairvoyance, published in the Lancet, vol. i. New Series, 1845.-p.581.

Nothing has been so degrading to the human mind; nothing has led to worse consequences, than the too great credulity of man; the evils that have arisen from it, have been far worse than any which have sprung from his scepticism. The latter, though it may arrest for a time the progress of truth, has this advantage, that it leads to the thorough sifting of the testimony on which truth depends, and finally tends to establish it on a firmer basis than if such doubts had never existed. The evil results of his too great credulity have been fearfully evidenced by the cruelties that have been 
inflicted by man on his fellow-man, during the darker ages, and of which there cannot be a better example than those cruelties which were practised on so many helpless beings, in consequence of his belief in witcheraft. We have too much confidence in the progress of knowledge, and the excellence of our laws, than to think that such scenes shall ever be again witnessed, at least in Great Britain. But though they may not be, errors as great and delusions as dangerous, though of a different character, may take possession, to a great degree, of the public mind. If the public, of the present time, should give credence to the many crude, false, and absurd statments, relative to mesmerism, which are every day foisted on them, we have no doubt that such belief would prove to be as pregnant of evil as any of the grossest superstitions of the middle ages. We certainly agree with Miss Martineau in the following observation, that if mesmerism (i. e., to the extent which its admirers would wish us to believe in it),

"Is a cheat, that it is no laughing matter. If large numbers of men can, age after age, be helplessly prostrated under such a delusion as this, under a wicked influence, so potential over mind and body, it is one of the most mournful facts in the history of man."

As Miss Martineau, and other writers on mesmerism, frequently refer, though we do not think in the best taste, to the miracles of Holy Writ, and the testimony on which they dèpend, we shall say, en passant, a few words on this subject. It would, we think, be of the utmost use to such writers to study more carefully the testimony on which the truth of Scripture miracles depends, and to imitate the plain narrative style with which they are recorded; the miracles of the New Testament were performed to prove the divinity of Christ, and the divine mission of his Apostles; they were intended to establish a great object, which, when effected, were no longer necessary, and of course ceased : that they would do so, we are told in Revelation,- - they were admitted to be contrary to the ordinary course of nature and experience, and totally inexplicable by human reason,-so also are the alleged marvels of mesmeric clairvoyance. But there is this remarkable difference between the miracles of Scripture and the latter, that the miracles of Scripture were of such a nature as to be incontestable by those who witnessed them; but such is not the case with regard to mesmeric clairvoyance. The impartial writer in Blackwood's Magazine thus expresses himself on this subject:

"Mr. Townshend has failed to convince us that all the facts in 
mesmerism are facts; and certainly, if he has failed, the herd of peripatetic lecturers, on the so-called science, are not likelyto have succeeded; but, although unconvinced of the marvellous, we are by no means indisposed to believe some of the abnormal phenomena of mesmerism. We have witnessed several mesmeric exhibitions. We have never seen any effect produced which was contradictory to the possible of human experience, in which collusion or delusion was fairly negatived. We insist on our right to doubt or disbelieve. The more startling the proposition, the more rigorous should be the proof. We have never seen the tests, which are applied to the most trifling novelty in physical science, applied to mesmeric clairvoyance, and withstood. The advocates of it challenge inquiry in print; but they shrink from, or sink under, experiment."

We are ready to admit, that some of the laws of nature, for instance the instincts which direct the lower animals, are as wonderful and as little discoverable by reason as any of the miracles of Scripture, or the alleged marvels of mesmerism, and of which all we can say is, that they are laws established by the Deity to serve as a substitute for reason. The existence of these laws is, however, incontestably proved by the clearest evidence, and they have been conformable to the experience of mankind in every age. What we have just been writing belongs more to the province of the theologian than to our's; we would not, therefore, have dwelt so much on it, but that we have been frequently asked by the admirers of mesmerism, how can you believe the testimony in favour of the miracles of Scripture and not our's?

Though the experiments made at the exhibitions we ourselves have witnessed of mesmerism, to our minds, were failures, we cannot refuse our assent to the truth of the accounts of so many credible witnesses, that occasionally a somnambulatic state may be induced by the so-called mesmeric influence, differing from ordinary sleep, or, in the words of the writer already quoted, "that a power may be exercised by one human being over another which will produce a comatose or cataleptic state."

As cases of amputation, extraction of teeth, divisions of tendons, and many minor operations, have been recorded, in which the patients are said to have suffered no pain while under the mesmeric influence, we certainly think that this writer has much reason for the following observation :

"Though we have never had an opportunity of witnessing such effects, we think that for the benefit to suffering humanity, the possibility, however remote, of their truth, deserves more calm and dispassionate inquiry, than appears hitherto to have been given them." 
At the same time we cannot but express our apprehension, that more mischief is likely to arise in a moral point of view from the practice of mesmerism, than any good that may be attained by it from the relief of physical suffering. In recommending us how to examine the phenomena of mesmerism, the author judiciously writes:

"We shall do our utmost to avoid the vices of partial advocacy which we censure; we moreover agree with $\mathrm{Mr}$. Townshend, that ridicule is not the weapon to be used. Satire, when on the side of the majority, is persecution : it is striking from a vantage ground, fair, perhaps, when the individual contends with the mass, as when an author writes to expose the fallacy of social fashion_but unfair, and very frequently unsuccessful, when directed against partially developed truths, or even against such phenomena as we believe mesmerism presents, viz., novel and curious psychical truths, overclouded with dense errors, of sometimes enthusiasm, and sometimes knavery. We shall soberly examine the subject, because we think that much good may be done by its investigation. The really skilful and judicious steer clear, from a fear of compromising their credit for common sense ; and while the caution necessarily attendant upon habitual scientific studies, dissuades the best men from meddling with that which may blight their bardly earned laurels, the public is left to be swayed to and fro by an under current of fallacious half truths, far more seductive and dangerous than absolute falsehoods. We cannot undertake to say thus far is true, and thus far false ; to mark out the actual limits of true mesmeric phenomena demands the very difficult and detailed inquiries, which, for the reasons just mentioned, have been hitherto withheld; but we think we shall be able to succeed in shewing, that though there be much error, there is some truth, and truth of sufficient importance to merit a calm and careful investigation. We may class the phenomena of mesmerism, as asseited by its professors, as follows :-

“ 1st. Sleep or coma, induced by external agency (partly mental, partly physical).

“ 2nd. Somnambulism, or, as called by Mr. Townshend, sleepwalking, i. e., certain faculties rendered torpid, while others are sensitive.

"3rd. Insensibility to pain, and other external stimuli.

" 4 th. Physical attraction to the mesmeriser, and repulsion from others; community of sensation with the mesmeriser.

5 th. Clairvoyance; or the power of perception without the use of the usual organs; and second sight, or the power of prediction respecting the mesmeric state, and remedial agencies.

" 6 th. Phreno-mesmerism, or the connexion between phrenology and mesmerism.

" 7 th. Curative effects."

First. As to the power of inducing coma, the author give voL. XXVII. No. 79. 
two very interesting cases which fell under his own observation; they bear the stamp of truth, and it is almost impossible not to give credence to them; the individuals on whom the mesmeric influence was exerted were both females; we would be glad to transfer these cases to our pages, but our limits will not permit. We shall take this opportunity of observing, that most of the cases we have read and heard of, in which the mesmeric influence proved effectual, were those of females. If it be the case, that the great majority of such cases belong to the fair sex, it is remarkable, as hysteria and catalepsy are almost exclusively confined to that sex. The author, however, extracts two cases of induced coma from Mr. Hare Townshend's work, which we strongly recommend to the perusal of our readers, in which both cases were men, and in which there could be no deception, as one was that of the celebrated professor of natural history, M. Agassiz, and the other of Signor Raniere, the historian.

3rdly. As to insensibility to pain, and other external stimuli, we have alieady made a quotation from what the author has said on this subject. He is evidently undecided on this point.

4thly. He appears to consider the experiments which he witnessed, to prove physical attraction towards the mesmeriser inconclusive.

5thly. We are glad to see, that he gives no credence whatever to the marvels attributed to mesmeric clairvoyance. As he makes several judicious remarks on this subject, we shall quote them, particularly as they form an admirable commentary, though not intended as such, to many of the doctrines advanced in Miss Martineau's letters, and may serve as most useful hints to many of our professional brethren, to assist them, not only in reasoning on mesmerism, but on all empirical systems. The author thus reasons:

"It is very properly argued, that our whole knowledge of the normal course of nature is derived from experience; that a law is a mere generalization from that experience, and is not any thing intrinsically or necessarily true. Thus, if the sun were to rise in the west to-morrow, instead of in the east, it would, at first sight, appear to be a deviation from natural laws, in other words, a miracle; if, however, the latter circumstance were wanting, after the first sensation of the marvellous had subsided, the philosopher would inquire, whether instead of being a deviation from a law, it were not a subordinate instance of some higher law, of which the period of history had been too short to give any coordinate instance; and if it were found, by a long course of experience, that in every 4000 years a similar retrocession of the earth took place, a new law would be establisbed. Ap- 


\section{Mesmerism.-Blackwood's Magazine.-Miss Martineau. 107}

plying this to mesmerism, it is said, our notions of sleep and waking, of sight and hearing, and if the probable limits and modes of sensation, are derived from experience alone ; we cannot estimate or uuderstand the modus agendi of a new sensation, because we have never experienced it. If, then, it be proved, by the acts of A., B., C., that they attain cognizance of objects by other means than those which any known organ of sensation will permit, you must admit the fact, and by degrees its rationale will become supported by the same means as all other truths are supported, viz., by habitual experience. The law is indeed nothing but its constant recurrence, under similar circumstances."

The author here cites an eloquent passage from Mr. Townshend's work, to give Mr. Townshend's own mode of enunciating what we have just quoted. This passage may appear to be rather tedious, and too abstract for many of our readers, but we believe that it suggests the best mode of reasoning which the advocates of mesmerism can have recourse to. To teach those who are sceptical on that subject, how to meet them on this ground, the author gives some excellent instructions. They are as follows:

"In order that the mesmeriser may support himself on this high ground, his proof must be demonstrative; he must be able to say, I ask not for faith, nor even a balanced mind, but doubt to the utmost. Examine with the most rigorous scepticism. I stand upon the facts alone. I offer no explanation, or, at least, I make their truth dependent upon no explanation. They are, or they are not. I will prove their existence, and 1 defy you to disprove them.

" It will not, we conceive, be denied, that one essential attribute of the social mind, a jealousy of credence in apparent anomalies, is a just and necessary guard upon human knowledge. If mere assertion were believed, every succeeding day would upset the knowledge of the preceding day, and, however high the character of the assertor of new and abnormal facts may be, he must not expect them to be received upon the strength of his assertion. The best men may be deceived, and the best men may be led astray by enthusiasm. When the slightest discovery in physical science is published, it is immediately assailed by doubts from every quarter, and its promulgator, if he be accustomed to research, and trained to scientific investigation, never complains of these doubts, because he knows the vast number of perplexing deceptions in which he has himself been entangled, and the caution with which he himself would receive a similar announcement.

"It is vain to cite instances of truths unappreciated by the age in which they were advanced. We deprecate, as much as any, the persecution with which, occasionally, men who have seen far in advance of their age, have been attacked; but the saying, ' malheureux celui qui est en avance de son siecle,' is not always true; if the new truth 
be difficult of demonstration, it will be proportionably tardy of reception, but if easy of proof, it is very rapidly received."

As an example of this, the author instances the discovery of Volta.

The results afforded by Mr. Babbage's calculating machine afford a beautiful illustration of this subject, and has been adduced as such in his so-called Ninth Bridgewater Treatise. The miracles of Scripture, as we have already remarked, are striking instances of occurrences contrary to the usual course of nature, and totally inexplicable by reason, which have met the tests laid down by our author. Some of the vast geological changes, such as the deluges, which have taken place, are instances of occurrences, that, perhaps, though not inexplicable according to the received laws of nature, are, certainly, contrary to all ordinary experience ; instincts, on the contrary, as we before remarked, are instances of laws totally inexplicable by reason, yet quite in accordance with our ordinary experience.

The author thus speaks of magnetism and electricity, as contrasted with mesmerism :

" Magnetism and electricity, moreover, often cited by Mr. Townshend, and, undoubtedly, the most surprising additions to human knowledge within the historical period, though abnormal, are not contradictory to experience; they were an entirely new series of facts, added to our previous store; they did not destroy or lessen the force of any previously received truths. Not so mesmerism; and, therefore, the more stringent should be, and is, the proof required."

We shall now quote some of the arguments, which, to our minds, seem very conclusive, by which the author demonstrates the fallacy of the reasoning with which Mr.Townshend endeavours to prove the conformity of the mesmeric marvels with general experience. In following our author, we must hold in view, that he is now reasoning according to the recognized laws of nature, and principles of physics:

"In short we think we do not unfairly express the author's (Mr. Townshend's) theory in the following query. As the application of the highest human powers (those of Newton, for instance) have resolved the transmission of light to the sensorium into the vibrations of an all-pervading ether, what is more probable than that a similar ethereal medium may convey sensations of objects through other channels? This may be, but another important ingredient is wanting, viz., organization, or definite molecular arrangement. Prick the eye, and by the resulting morbid derangement, change the molecular arrangement of its particles, and vision is destroyed. Puiverize the glass through 
which you look and it is no longer transparent. The ether (if there be an ether), in the pores of these substances, can only convey correct impressions when these particles have a definite arrangement; but the mesmeric ether ( $M r$. Townshend's) is dependent upon no such necessity. Density and tenacity, opacity and transparency, homogeneous or heterogeneous, are all equally penetrable; and, what is more strange, the mesmeric ether conveys correct and not distorted impressions. The same perception of form which is conveyed throngh air, is conveyed through the cover of a book, through the bones of a skull, or the muscles of the stomach. And still more extraordinary, this impression is identical as to the mental idea it conveys, with that conveyed in the normal manner through the eye. The mesmeric ether has therefore not only the power of conveying impressions, but of preserving their continuity through any impediment. The formal impressions of a chair or table which are conveyed by ordinary vision in right lines to the retina, if these lines be distorted by an intervening want of uniformity in the matter, are proportionably distorted. Let striæ of glass, of different density, intervene in an optical lens, and the objects are distorted; increase the number of striæ, the object is more imperfect; and carry the molecular derangement further, opacity is the result. Transparency and opacity then, viewed apart from all hypothesis, resolve themselves into organization or molecular arrangement : yet, by the mesmeric medium, a chair or table is conveyed to the recipients in its distinct form, or, what amounts to the same thing for the argument of conformity, they give to the mind distinct ideas of these objects. If, therefore, there be a mesmeric medium, which, being a purely hypothetic creation, cannot be disproved, its requisites must be so totally at variance with the requisites of ordinary ethereal media that none of the rules which can be applied to this can be applied to that.

"Many of the objects of vision-all, indeed, by which reading is effected-are purposely constructed to suit the peculiar organization of the eye; they are artifices specially appropriated to give sensations. Thus black letters are printed on white paper, because experience has told us that black reflects no light, while white reflects all the incident light. If we wish to read by another sense we adapt onr object to such a sense; thus for those who read by the finger, raised letters are prepared, differing from the matrix in position, but not in colour. If we read by the ear we address it by sounds, and not by forms or colours, and it wonld be far from impracticable to read by smell or taste, by associating given odours or given tastes with given ideas.

"In all this, however, each sense requires a peculiar education and long training; it is only by constant association of the word table with the thing table that we connect the two ideas; but mesmeric clairvoyance not only conveys things as things in all their proper forms and colours, without the intervention of the usual senses, but it also dispenses with education or association, or instantly adapts to a new sense the education hitherto specially and only adapted to another." 
We may here refer to the well known instance cited by Locke to shew how little we can appreciate by another sense the ideas perceived by one sense, of the blind man who said the colour scarlet was like the sound of a trumpet; also to the blind man spoken of in Scripture, who, when asked, after being restored to sight, what he saw, said, men like trees walking.

The learned writer sums up his arguments by saying:

"lst, That without undervaluing testimony, mesmeric clairvoyance is not sufficiently proved by competent witnesses to be admitted as a fact.

" 2nd, The reasoning in support of it is insufficient, and, in most cases, fallacious."

And finally says on the subject :

"Perhaps the best arguments employed by Mr. Townshend in favour of the possibility of clairvoyance are the authenticated cases of normal sleep-walking. These have been very little examined, but appear in one respect strikingly to differ from mesmeric coma. The eyes of the somnambulist are said to be open, and therefore there is every optical power of vision, and an increase of ordinary visual perception is all that is requisite. The acts performed by the sleep-walker are, moreover, generally those to which he is habitually accustomed, and when this is not the case he fails, as many disastrous accidents have too fatally testified."

As to the sixth category, phrenomesmerism, or the connexion between phrenology and mesmerism, the following is what our author observes:

"Viewed abstractedly, the attempt to support, by the assumed accuracy of one science, at best in its infancy, and confessedly fallible, another still more so, is making too large demands upon public credulity, to require much counter argument."

The author gives no opinion of his own relative to the curative effects of mesmerism. He merely confines himself to the quotation of a case, apparently of amaurosis, from Mr. Hare Townshend's work. The effects of it in this case, to our minds, was anything at all but satisfactory.

As to the means whereby the mesmeric effects are induced, our author makes the following observations :

"From the remark made by the mesmeriser (the gentleman who. was the mesmeriser in the two cases which we have already mentioned that our author witnessed), viz., that the only influence he was conscious of exerting was that of a fixed determined stare, this may possibly afford some key to a more philosophical examination of these curious phenomena. 
"The fabled effects of the basilisk, the serpent, and the evil eye, have probably all some facts for their foundation. The effect of the human eye in arresting the attacks of savage animals is better authenticated, and its influence upon domestic animals may be more easily made the subject of experimental proof. Let any one gaze steadily at a dog half-dozing at the fire-side, the animal will, after a short time, become restless, and, if the stare be continued, will quit his resting-place, and either shrink into a corner or come forward and caress the person staring. How much of this may be due to the habitual fixed look of stern command with which censure or punishment is accompanied it may be difficult to say, but the fact undoubtedly is, that some influence, either innate or induced, is exercised. Again, those who in society habitually converse with an averted glance, we generally consider wanting in moral force. We doubt the man who doubts himself. On the other hand, if, in conversation, the ordinary look of awakened interest be prolonged, and the eyes are kept fixed for a longer period than usual, an embarrassed and somewhat painful feeling is the result; an indistinct impulse makes it difficult to avert the eye, and at the same time a conscionsness of that impulse is an inducement to avert it. We lay no undue stress on these phenomena ; but they are phenomena, and fair subjects for scientific investigation. An explanation of mesmerism has been sought in the physical effect of the stare alone; thus it is said that if a party look intensely at a prominent object fixed to his forehead, he will in time be thrown into a mesmeric coma. There is more in it, we think, than this; there is an influence excited by that nearest approach to the intercourse of soul, 'the gaze into each other's eyes' the extent and source of which are unknown. The schoolboys' experiment of staring out of countenance, is not so bad a test of moral power, as it would, at first sight, be deemed to be."

Whatever may be the nature of the effect here produced, the author, we think, lays too much stress upon what he terms moral power. We do not know whether he can bring under this head the dazzling effect of extreme beauty*"the might - the majesty of loveliness."-He might, in our opinion, have alluded more fully to the effects of monotonous sounds, and uniform motions ; of the latter, the composing of infants to sleep by means of the rocking of the cradle, is a familiar instance; the frequent repetition of the same idea, or of similar ideas, such as the counting of numbers, tends also strongly to induce sleep.

Of Miss Martineau's letters, after apologising for not

* Erzog in einz'ges wunderschönes kind, Zwar wollte man in unserm Dorfe schwören, Ein jeder werd' in ihrer Nähe blind. 
noticing them more at length, in consequence of the lateness of their publication, he thus observes, in which we agree with him :

"They have not induced us to alter anything we have written; they have indeed confirmed one remark made above. The effects described by Miss Martineau as produced upon herself, are credible, and not preternatural, while the second sight of the girl $\mathrm{J}$. is preternatural, and not credible, i. e., not credible, as preternatural, otherwise easily explicable.

"In this, as in every mesmeric case, the marvellous effects are developed by the uneducated - the most easily deceived - and the most ready to be deceivers.

"The clairvoyant writers have greatly the advantage of the sceptics in one respect, viz., the public interest of their communications. Every one reads the descriptions of new marvels; few care to examine the arguments in contravention of them.

With regard to Miss Martineau's own case, we shall say but little, as we own, notwithstanding Dr. Greenhow's account of it, that it is to us a very obscure one. In justice, however, to Dr. Greenhow and Sir Charles Clarke, we consider it our duty to make a few extracts from the published account of the former physician, relative to the prognosis and treatment, as it is at variance with the following statement in Miss Martineau's letters :

"Nobody in the world would undertake to say I was wrong in seeking even recovery by any harmless means, when every other hope was given up by all, and it was not recovery that was in my thoughts, but only solace. It never presented itself to me as possible, that disease so long and so deeply fixed could be removed, and I was perfectly sincere in saying, that the utmost I looked for, was release from my miserable dependence on opiates."

The following passages are extracted from the condensed account in the Lancet (vol. i. 1845.-p. 19), of Dr. Greenhow's medical report of the case of Miss Martineau. "In Sir Charles Clarke's written opinion, dated September30th, 1841, it is stated, 'I have known such complaints as Miss M.'s subside, and I would employ for this purpose the continued external use of iodine ointment." Dr. Greenhow then says : " but which my patient refused to carry into effect. Therefore I proposed a course of iodide of iron, which, with short intervals, was persevered in till July or August, 1844. The distressing sickness was thus greatly mitigated, the appetite improved, and increased health and mental energy shewed itself." He then gives the patient's own opinion of its effects 
Mesmerism.-Blackwood's Magazine.-Miss Martineau. 113

in September, 1843, which is much to the same effect, and observes :

"That oftener than once I have used the expression, that probably before long, she would take up her bed and walk. In this case, the advocates of mesmerism may try to find arguments in support of their opinions; but the experienced practitioner will have little difficulty in bringing the whole into harmony with the well-established laws of human physiology. The condition of the uterus, in 1844 , is but the natural sequel of progressive improvements begun in April, and the time had arrived when a new and powerful stimulus only was required to enable the enthusiastic mind of my patient to shake off the nervous symptoms."

"A glance at the prescriptions employed, except on particular emergencies, during the last three years, will shew the error of supposing that Miss M. was in the habit of seeking relief in large and immeasured doses of opium."

That Miss Martineau, as is evident from her letter, should be a great enthusiast on the subject of mesmerism, is very excusable, as she attributes to it the relief she obtained. Whether this was the case or not we consider very doubtful, most probably it was owing to the excitement of her imagination on that subject. Miss Martineau is too good a reasoner not to be aware, that if recovery ensues subsequent to the use of any supposed remedy, that it does not follow, because it is post hoc, that it should be propter hoc; it is not until recoveries frequently take place after the use of the same remedy in similar cases, that we can say that they result from that remedy. Dr. Cheyne has remarked, and indeed it is generally well known to physicians, that much of the success attendant on the practice of eminent physicians, is owing to the confidence that patients have in their skill. The mere confidence that a credulous person may repose in the treatment of an empiric, may in some cases induce a cure, though the remedy administered be totally inefficacious; this, however, is no argument in favour of empiricism, because, for the few cures that may be thus effected, an infinity of mischief may arise, from the public thus being led to place a false confidence in empiricicism, and thus that opportunity of producing relief, by the proper exercise of art, may be lost.

We shall give two cases, which came under our own observation, which, we think, well illustrate the effect of the mind over disease. One was a case of hysteria, that of a young lady who had lost the use of her lower limbs, in con-

voL. XXVII, No. 79. 
sequence of the hysterical affection, and had not been able to walk for a long period. Having been recommended change of air and scene, she merely went, for a short time, on a visit to an agreeable family of her acquaintance, and quickly recovered. The other was that of a gentleman, who was seized with hemiplegia of the right side from apoplexy : after having been for some time submitted to treatment, he recovered the use of the lower extremity, but his arm continued for some time paralysed. One morning, however, a frieud to whom he was much attached, and whom he had not seen for some time, unexpectedly visited him, by a sudden effort of the will, he extended his right arm, which had been previously paralysed, to shake hands with him, and ever since retained the use of his arm.

We fully approve of what Miss Martineau recommends, with regard to the investigation of the phenomena of mesmerism, "to sit down patiently before the great subject (as she styles it), watching and waiting for knowledge to arise and come forth ;" but we think that the fair authoress might better employ her time, as her mind, in our opinion, is of too enthusiastic a stamp, to make correct deductions from what she observes on this subject. This we shall endeavour to shew, from her account of the mesmeric clairvoyance of the girl $\mathbf{J}$. Of this young woman, she states:

" When I entered my lodgings, nearly five years ago, I was waited upon by my landlady's niece, a girl of fourteen; from that time to this she has been under my care, and now, at the age of nineteen, she has all the ingenuousness and conscientiousness, that won my respect at first, with an increased intelligence and activity of affection."

After this admission, it appears to us almost impossible, but that the girl must have heard much about Miss Martineau's previous life, either from Miss Martineau herself, or her friends ; and still Miss Martineau says:

"I cannot here detail the wonderful accuracy with which she related, without any possible knowledge of my life ten and twenty years ago, the origin and progress of my ill health, of the unavailing use of medical treatment for five years, and the operation of mesmerism upon it of late."

We shall give one extract more, to shew Miss Martineau's credulity on this subject:

"The next evening (Monday, October, 14th), I did not coine up as usual to our seance. There was aftliction in the household. An aunt (by mariage), of J.'s, Mrs. A., a good woman I have long known, lives in a cottage at the bottom of our garden. Mr. A.'s son, J.'s 


\section{Mesmerism.-Blackwcod's Magazine.-Miss Martineau. 115}

cousin, was one of the crew of a vessel which was this evening reported to have been wrecked near Hull. This was all that was known, except that the owner was gone to Hull to see about it. J. was about to walk to Shields, with a companion, to inquire, but the night was so tempestuous, and it was so evident no news could be obtained, that she was persuaded not to go. But she was too much disturbed to think of being mesmerized. Next morning there was no news. All day there were flying reports - that all hands were lostthat all were saved, but nothing like what afterwards proved to be the truth. In the afternoon (no tidings having arrived), we went for a long drive, and took J. with us. She was with us in another direction till tea-time; and then on our return, there was no tidings; but Mrs. A. was gone to Shields to inquire if letters had come; she would bring the news in the evening. J. went out on an errand while we were at tea, no person in the place having then any means of knowing about the wreck, and on her return, she came straight up to us for her seance. Two gentlemen were with us that evening, one from America, the other from the neighbourhood. I may say that we noted down at the moment what J. said, and that on this evening there was the additional security of my American friend, repeating to me on the instant (on account of my deafness), every word as it fell.

J. was presently asleep, and her mesmerizer knowing the advantage of introducing the subject on which the mind had previously been excited, and how the inspiration follows the course of the affections, asked, as soon as the sleep was deep enough, "Can you tell us about the wreck?' J. tranquilly replied, 'Ob! yes, they're all safe; but the ship is all to pieces.' 'Were they saved in their boat?' 'No, that's all to pieces.' 'How then?' 'A queer boat took them off ; not their bnat.' 'Are you sure they are all safe?' 'Yes, all that were on board ; but there was a boy killed. But I don't think it was my consin.' 'At the time of the wreck?' 'No, before the storm.' 'How did it happen ?' 'By a fall.' 'Down the hatchway, or how ?' No, he fell through the rigging from the mast.' She presently observed, 'My aunt is below, telling them all about it, and I shall hear it when I go down.'

"My rooms being a selection from two houses, this 'below' meant two stories lower in the next house. * * * * *

"Two evenings afterwards $J$. was asked, when in the sleep, whether she knew what she related to us, by seeing her aunt telling the people below? to which she replied, 'No, I saw the place and people themselves like a vision.'

"Such was her own idea, whatever may be the conjectures of others."

We know what our conjectures are. Such is a specimen of the evidence with which Miss Martineau would induce the public to believe in the miraculous wonders of clairvoyance; the mind indeed must have been blinded by enthusiasm, not to have at once suspected collusion 
and deception in this case. What could have been more likely than, when the girl went out upon an errand, that she saw either her aunt, or some other person, who informed her all about the shipwreck; and was it not a most suspicious circumstance, that on her return she should have asked for her seance. Miss Martineau may have a very high opinion of this girl's truthworthiness, but she is not to expect the public to be equally credulous, so as to believe in all her mesnueric revelations. It may be asked, what inducement could this young woman and other persons famed for their mesmeric power's have to deceive? The love of notoriety and applause, and the prospect of gain, may be an inducement to some. In a recent number of the Lancet (for Feb. 1st, 1845), there is published in a note by the subeditor of the Lancet to an account of the Rise and Progress of Mesmerism, by Dr. Radcliffe Hall, the following extract from a letter by Dr. Perrochaud, of Boulogne Sur Mer, in answer to some inquiries concerning a woman named Petronille, who performed great mesmeric marvels:

"It is quite true that the famous Petronille, who was at one time considered an extraordinary somnambulist, confessed to me some days before her death that she had constantly deceived the good faith of those who performed magnetic experiments on her. She gave me many details respecting the tricks she resorted to in order to abuse the learned and conscientious persons who afterwards, on those experiments, founded memoirs and reports extremely favourable to magnetism. 'I was very often wrong,' she said, ' but when I approached the truth or had guessed nearly right, all present clapped their hands and exclaimed it was a miracle, and this made up for my mistakes."

In Miss Martineau's preface there is mention made of a new literary organ for philosophical mesmerisers being already in contemplation. Should all the writers for it be as enthusiastic on the subject as Miss Martineau herself, we would recommend a name for it that has been adopted for that of a journal supported by contributions from the pens of the inmates of a lunatic asylum in Dumfries-it is styled the "New Moon." We do not write this to discourage our readers from a fair inquiry, but to dissuade them against giving the reins to their enthusiasm.

We are heartily glad of the fair authoress's recovery, to whatever cause it may be owing, and earnestly hope, that she will devote her talents to objects more suited to them than experiments in mesmerism; or if she be too much wedded to that so-called science to give it up, that she will attend to her own excellent advice : "Let experience, carefully ob- 
tained, be wisely collected and philosophically communicated." Otherwise the result will be likely to prove more mischievous than useful. Let her not be like those-

" Who greedily pursue

Things wonderful instead of true.

Hold no truth worthy to be known,

That is not huge and overgrown."

We must, however, do her the justice to say, that we believe her to be actuated by no other motive than the investigation of truth for the good of mankind.

Elements of the Comparative Anatomy of the Vertebrate Animals. By Rudolph Wagner, M. D., Professor of Comparative Anatomy and Physiology in the University of Göttingen, \&c. Edited from the German, by AlFred TulK, M. R. C. S. London, 1845.

Although several very excellent treatises on the subject of comparative anatomy have lately issued from the British Press, yet the want of some good elementary work, which, in a compendious form and at a moderate expense, would furnish the student with the present amount of our knowledge upon the anatomy of vertebrate animals, has hitherto been a subject of complaint.

This want has been admirably supplied by the "Lehrbuch der Zootomie," from the pen of Professor Wagner, who has already attained so high a reputation among the medical profession, through his Elements of Physiology, translated by Dr. Willis.

The volume before us contains a clear and concise description of the tegumentary, osseous, muscular, nervous, digestive, circulatory, respiratory, and generative systems; the organs of the senses, the urinary organs, and particular organs of secretion in mammalia, aves, reptilia, and pisces.

At the end of each class is inserted a list of the best authors who have written on its anatomy, forming a most useful and complete bibliography of the subject.

In his selection of Dr. Wagner's manual for translation, Mr. Tulk has evinced much judgment; and for the manner in which he has edited it, he deserves great credit. We strongly recommend it to the Profession, as a work which should be in the possession of every one who wishes either 
to keep up his knowledge, or to enter upon the study of the comparative anatomy of the vertebrate animals : and we sincerely trust that the encouragement which it may receive, will enable Mr. Tulk, at no distant period, to give the promised atlas of illustrative plates.

An Explanation of the real Process of "Spontaneous Evolution of the Foetus." By John C. Douglass, M. D., \&c. Third Edition.

Any man who offers to the public a new and different explanation of a familiar occurrence, must expect to meet with considerable opposition to his views, and still more, if the occurrence be rare, the opportunity of witnessing the entire process infrequent, and above all, if his explanation be opposed to that received " in the schools." This was the early fate of Dr. Douglass's tract, but the respected author has lived to see not only the accuracy of his explanation admitted, but also to find it universally admitted that he was the first to give the true one.

On this account, and for the credit of our country, we are glad to see a reprint of this valuable monograph, and we are sure that it will find its way into the hands of all our obstetric readers.

At the present time it will not be necessary for us to enter into a minute consideration of the subject: a slight sketch may suffice.

The first case on record was observed by Dr. Denman in 1772 , and the second in 1773 , by the same distinguished practitioner, who applied to the process the term "spontaneous evolution," from the opinion that the child turned upon its axis. We have his letter to Dr. Douglass informing us that the fact, as well as the theory, was, for a long time, disbelieved.

Dr. Denman conceived that the body of the child being doubled, successive pains drove down the breech, and as this descended, the shoulder ascended into the uterus. Dr. Douglass, on the contrary, affirms, " that not one line of the arm, or of any other part of the child, once descended, are withdrawn into the uterus."

Dr. Douglass's observations were published in 1811, and though at first received with doubt, further observations have completely verified them, and they have superseded those of Denman and others, who succeeded him. We have ourselves 
Dr. Douglass on "Spontaneous Evolution of the Fotus." 119

had an opportunity of witnessing the whole process minutely, from first to last, and can bear testimony to the admirable accuracy of our author's description.

After mentioning that in these cases the " shoulder of the child is forced very low into the pelvis," just previous to the occurrence, he adds :

"I cannot comprehend how successive repetitions of the same propelling power which forced the child into this situation, should subsequently, at any period, produce a counter-effect, causing the shoulder to retreat into the uterus. The fact, however, is, - that the shoulder and thorax, thus low and impacted, instead of retreating into the uterus, are, at each successive pain, forced still lower, until the ribs of that side, corresponding with the protruded arm, press on the perineum, and cause it to assume the same form as it would by the pressure of the forehead in a natural labour. At this period, not only the entire of the arm, but the shoulder, can be perceived externally, with the clavicle lying under the arch of the pubis. By further uterine contractions, the ribs are forced more forward, appearing, at the os externum, as the vertex would in a natural labour; the clavicle having been by degrees forced round in the anterior part of the pubis, with the cranium looking towards the mons veneris. ...... The lower part of the same side of the trunk presses on the perineum, with the breech either in the hollow of the sacrum, or at the brim of the pelvis, ready to descend into it; and by a few further uterine efforts the remainder of the trunk, with the lower extremities, is expelled...... The breech is not always expelled sideways, as the upper part of the trunk had previously been ; for during the presence of that pain by which the evolution is completed, there is a twist made about the centre of the curve (formed by the child), at the lumbar vertebra, when both buttocks, instead of one side of them, are thrown against the perineum, distending it very much, and immediately after the breech, with the lower extremities, issues forth, the upper and back part of it appearing first, as if the back of the child had originally formed the convex, and its front the concave side of curve."-pp. 25, 26, 27.

In confirmation of the correctness of this description, $\mathrm{D}_{1}$. Douglass refers to cases by Drs. Gooch, F. Ramsbotham, Wardsworth, and Churchill, and we may add one by Dr. Neligan, now of this city.

Our space will not permit of our quoting Dr. Douglass's cases, nor do we think it necessary. We most cordially recommend this little essay to all our readers, as the work of a highly intelligent practitioner of great observation and rigid accuracy; and we regard it with especial interest, as that which (along with Dr. Clarke's reports and papers) laid the foundation of the high repute of Dublin as a school of midwifery. 